\title{
Blog: ferramenta terapêutica ocupacional ${ }^{1}$
}

\author{
Miryam Bonadiu Pelosi \\ Terapeuta Ocupacional, Doutora em Educação pela Universidade do Estado do Rio de Janeiro - UERJ, \\ Professora Adjunta, Universidade Federal do Rio de Janeiro - UFRJ, RJ, Brasil
}

\begin{abstract}
Resumo: Um blog é um sítio eletrônico cuja estrutura permite a atualização rápida, a partir da postagem de artigos, ou posts. Em um blog podem ser combinados textos, imagens, vídeos e links para outros blogs, e o que torna o blog uma ferramenta potencial de trabalho terapêutico são as facilidades de uso que os sistemas de criação e edição disponibilizam, dispensando o conhecimento de recursos mais complexos de programação. Como em toda atividade, o profissional precisa conhecê-la para usá-la como um recurso terapêutico, mas essa é gratuita, simples, pode ser realizada em etapas e com diferentes graus de complexidade. O blog pode ser utilizado como organizador de ideias, um local onde o usuário tem que decidir o que é pertinente ser postado, com qual vocabulário e para qual público; como um espaço para dividir experiências ou como parte integrante da elaboração de um livro de história. Para apoiar essa discussão, três casos, onde o blog foi utilizado como recurso terapêutico, foram apresentados. No primeiro, um menino de 12 anos, com diagnóstico de síndrome de Asperger, construiu um blog sobre personagens infantis; no segundo, um grupo de adolescentes, com dificuldades no processo de inclusão escolar e de inserção social, criou um blog para contar suas aventuras; e, finalmente, o terceiro caso relatou a história de uma moça com quadro de paralisia cerebral, que escreveu e publicou um livro e um blog com auxílio das estratégias de comunicação alternativa. Como argumentos para a discussão foram abordados temas como: a atividade como recurso terapêutico; os diferentes usos do blog pela rede mundial de computadores; e a possibilidade de utilização do blog como recurso terapêutico ocupacional para pessoas com histórias de vida singulares, com habilidades, limitações e desejos tão diversos.
\end{abstract}

Palavras-chave: Blogging, Terapia Ocupacional, Rede Social.

\section{Blog: occupational therapy tool}

\begin{abstract}
A blog is a site whose structure allows fast articles postage update, or posts. In a blog, texts, images, videos and links to other blogs can be combined, and what makes it a potential therapeutic working tool are the users' friendly resources provided for creating and editing systems, which do not require complex knowledge of programming resources. As in any activity, the professional needs to know it well before being able to use it as a therapeutic resource, but this one is free of charge and it can be performed in gradual steps at different complexity levels. A blog can be used as an idea-organizer, a site where the user decides what is pertinent to be posted, which vocabulary to be used, and the target public, as in a space to share experiences or an integral part in the elaboration of a history book. To support this discussion, three cases where blogs were used as therapeutic resources were presented. In the first case, a 12-year-old boy diagnosed with Asperger's Syndrome created a blog about children characters; on the second, a group of adolescents with school and social inclusion difficulties developed a blog to tell their adventures; finally, the third case told the story of a girl with cerebral palsy who wrote and published a book and a blog with the help of alternative communication strategies. The following themes were addressed as topics for the discussion: activity as therapeutic resource; the different uses of blogs in the worldwide computers net; and the possibility of using blogs as occupational therapeutic resources for people with singular life histories, with very diverse abilities, limitations and desires.
\end{abstract}

Keywords: Blogging, Occupational Therapy, Social Networking.

Autor para correspondência: Miryam Bonadiu Pelosi. Faculdade de Medicina, Universidade Federal do Rio de Janeiro, Rua Professor Rodolpho Paulo Rocco, 325, Prédio do CCS, Bloco K, Sala 26, Cidade Universitária, Ilha do Fundão, CEP 21910-590, Rio de Janeiro, RJ, Brasil, e-mail: miryam.pelosi@gmail.com

Recebido em 1/9/2011; $1^{\text {a }}$ Revisão: 16/12/2011; 2a Revisão: 12/7/2012; Aceito em 24/8/2012. 
A Terapia Ocupacional significa o uso terapêutico das atividades da vida diária com pessoas ou grupos que têm, ou estão em risco de desenvolver, disfunçôes que levem à limitação para a realização de atividades, ou que ocasionem restriçôes de participação em papéis e situaçôes em diferentes contextos como a casa, a escola, o trabalho ou a comunidade (AMERICAN..., 2002).

Para que essa atividade seja significativa ao cliente, pessoa ou grupo de pessoas, o terapeuta ocupacional precisa conhecer as demandas da atividade proposta, a série de habilidades envolvidas em seu desempenho e os vários significados culturais que podem ser atribuídos a elas.

Com o avanço da tecnologia, novas atividades vêm surgindo, como as que podem ser realizadas no computador e que permitem a expressão escrita, o uso de imagens ou vídeos. Essas novas atividades, como escrever pequenos textos em um blog, podem ser realizadas por uma única pessoa ou por um grupo delas, e vistas como terapêuticas pelos terapeutas ocupacionais.

Um blog, uma contração do termo em inglês web $\log$, é um site cuja estrutura permite a atualização rápida, a partir da postagem de artigos ou posts. Estes são, em geral, organizados de forma cronológica inversa, tendo como foco a temática proposta do blog.

O blog foi criado em 1997 por John Barger, editor do site Robot Wisdom, e rapidamente se tornou popular. Em 2008, o site de busca Technorati, especializado em registrar os blogs existentes na internet, já contava com mais de 112 milhôes de usuários ao redor do mundo, e afirmava que $120 \mathrm{mil}$ novos blogs surgiam na rede todos os dias. No Brasil, os blogs só começaram a ser difundidos entre os anos de 2000 e 2001, e também se tornaram muito populares (LUCCIO; NICOLACIDA-COSTA, 2010).

No início, os blogs eram usados como espaço para escrever sobre si mesmo, mas atualmente são utilizados com múltiplas finalidades: jornalísticas, esportivas, literárias, de humor, fofocas, economia, entre outras.

Estudos como o de Goldman, Cohen e Sheahan (2008) apontam para as possibilidades do uso do blog, como ferramenta educacional, em pequenos seminários nos cursos de formação. Os resultados apontam para a ampliaçáo de oferta de oportunidades de participação e aumento da interaçáo e aprendizagem dos estudantes, principalmente quando permitem e estimulam comentários.

Outros discutem o uso do blog como diário virtual, como o estudo de Subrahmanyam et al. (2009), que pesquisou 195 blogs de adolescentes, entre 14 e 18 anos, escritos na língua inglesa. Para a pesquisa foram realizadas três entradas em cada um dos blogs, que resultaram em dados relativos à autoapresentação dos autores, ao formato, estilo, conteúdo e tom dos textos. Como resultado, os autores encontraram "blogueiros" predominantemente do sexo feminino, que viviam nos Estados Unidos, com idade entre 15 e 16 anos. Os bloggers analisados apresentavam, em sua maioria, os nomes dos usuários, as fotografias e os dados sobre sexo, idade e localização de seus escritores. A maior parte das postagens utilizava textos com narrativas reflexivas e continha temas relacionados aos seus pares e sua vida cotidiana. Os autores dos blogs pareceram estar criando histórias para refletir sobre as pessoas e os acontecimentos em suas vidas. Os resultados sugerem que os contextos on-line e off-line dos adolescentes participantes do projeto estão psicologicamente ligados.

Ainda sobre a perspectiva de respostas sobre o porquê de os adolescentes escreverem em diários na rede, Lima e Santiago (2010) investigaram 50 blogs de adolescentes e identificaram como principais motivos o interesse em escrever sobre si, a busca de amizades e a importância em falar sobre a adolescência.

Outro uso que vem sendo dado às diferentes ferramentas da internet é a de discussão de casos entre profissionais (OMURTAG et al., 2012; GWOZDEK; KLAUSNER; KERSCHBAUM, 2008) e terapeutas ocupacionais de todo o mundo, que têm escrito sobre suas experiências ou sobre assuntos em que são especialistas, disseminando informaçōes e opiniōes.

Um blog pode ser escrito por uma única pessoa ou por um número variável de indivíduos. Muitos blogs fornecem comentários ou notícias sobre um assunto em particular, outros funcionam mais como diários on-line.

Em um blog podem ser combinados textos, imagens, vídeos e links para outros blogs. Os leitores podem deixar comentários a respeito de determinada postagem e acompanhar o que uma pessoa escreve sobre um assunto especial.

Para que pessoas com deficiência tenham acesso à autoria de um blog pode ser necessário o uso de recursos de tecnologia assistiva. O acesso ao computador pode ser facilitado com acionadores, tela ampliada, tela sensível ao toque, teclado com colmeia, teclados virtuais, ou o usuário pode necessitar de recursos de comunicação alternativa para se comunicar.

O terapeuta ocupacional avaliará as necessidades do usuário, suas habilidades físicas, cognitivas e sensoriais. O profissional avaliará a atividade e a 
receptividade do indivíduo quanto à modificaçáo ou à utilização da adaptação necessária para a participação e, ainda, promoverá a instrução do uso apropriado do recurso de tecnologia assistiva (CANADIAN..., 2003).

A especificidade do trabalho do terapeuta ocupacional, na área de tecnologia assistiva, envolve a ênfase que é dada na função, e esta possibilita a ele estimular as potencialidades do usuário, reduzindo a interferência da deficiência na realizaçáo de suas atividades (SHUSTER, 1993; PELOSI, 2007).

$\mathrm{O}$ que torna o blog uma ferramenta potencial de trabalho terapêutico são as facilidades que alguns sistemas de criação e edição disponibilizam, dispensando o conhecimento de $\mathrm{HTML}^{2}$.

Como toda ferramenta terapêutica, o profissional necessita conhecê-la para que possa utilizá-la com um recurso, mas essa é gratuita, simples, pode ser realizada em etapas e desenvolvida a partir da construção de textos, ou agregando uma série de conhecimentos mais elaborados como o uso de imagens ou edição e postagem de vídeos.

O blog pode ser utilizado como organizador de ideias, um local onde temos que decidir o que é pertinente ser postado, com qual vocabulário e para qual público; como um espaço para dividir experiências, ou como parte integrante da elaboração de um livro de história.

Para apoiar essa discussão, três casos serão apresentados. Os nomes são fictícios e os endereços dos blogs não serão revelados, para que cada "blogueiro" seja conhecido no mundo virtual pelo que quiseram revelar em seus posts, e não a partir da análise de sua terapeuta ocupacional.

No primeiro deles, um menino de 12 anos, com diagnóstico de síndrome de Asperger, construiu um blog sobre personagens infantis.

João é um menino que anda, faz todas as trocas posturais, mas apresenta dificuldades para realizar atividades psicomotoras como pular em um pé só, saltar, correr atrás de uma bola, agarrar e soltar, em uma situação dinâmica. Suas dificuldades psicomotoras o distanciam dos jogos rápidos como futebol, tênis, basquete, queimada, pega-pega ou outras tantas atividades que acontecem no recreio de sua escola.

A coordenação motora fina também apresenta problemas, principalmente na escrita manuscrita, em que a letra é de difícil compreensão, com tamanho ampliado para a pauta convencional do caderno.

A comunicação oral está bem desenvolvida, e João é capaz de relatar fatos. Ele adora ler e contar histórias, mas os textos com mais abstraçáo continuam sendo um problema. A "moral da história" e os "ditos populares" ainda são um mistério.

As relaçóes sociais avançam a cada dia, mas até então é muito mais interessante ver vídeos ou brincar com bonecos do que brincar com crianças da sua idade. Fechando o tripé de diagnóstico da síndrome de Asperger, João tem interesse restrito por vídeos e personagens da Disney.

A proposta de criação de um blog surgiu em uma das sessões em que ele estava procurando vídeos de personagens da Disney no YouTube ${ }^{3}$.

De abril a agosto de 2011, João postou 21 textos sobre diferentes personagens. Apesar de ter iniciado com os personagens do Rei Leão, seus favoritos, teve que ampliar o interesse para deixar o seu blog interessante para um número maior de pessoas.

A cada postagem ficou mais autônomo na busca das imagens, nos procedimentos de salvar e recuperar a imagem no post, na procura por vídeos pertinentes ao tema trabalhado e sua inserção. Sua escrita no computador ficou mais coerente, pois a cada texto fazíamos a revisão ortográfica e sintática das frases.

Sua autoestima aumentou quando percebeu que era o único em sua casa que tinha um blog e que sabia gerenciá-lo, e principalmente quando descobriu que muitas pessoas entravam no seu blog, que já tem mais de 32 mil acessos.

Enfrentou comentários on-line que desafiaram seus conhecimentos, e teve que lidar com a postagem de colegas, quando começou a se desinteressar pelo trabalho.

O blog mostrou ser uma ferramenta fundamental no desenvolvimento de Joăo. E trouxe mais autonomia e participação nas outras atividades que antecediam o momento de escrever no blog, nas sessóes de Terapia Ocupacional. Seu comportamento se modificou, e ele passou a planejar as etapas da atividade criando uma sequência que iniciava com a escolha do personagem, a busca de informaçóes no Google ${ }^{4}$ para complementar as informaçôes que já sabia sobre o tema, a procura por imagens no Google Imagens ${ }^{5}$, realizando a tarefa de salvar as figuras, e a pesquisa do vídeo no YouTube. Com a evolução do trabalho, passou a realizar as postagens em todas as suas etapas, até a publicação. Aprendeu a considerar o interesse de seus leitores e ampliou o repertório de interesse, passando a escrever sobre personagens de histórias diferentes da do Rei Leão, seu maior centro de interesse. João ganhou status na família. Ele passou a ser o único membro que era "blogueiro", e esse fato foi sinalizado diversas vezes por seus familiares. 
O segundo caso relata o trabalho de um grupo de adolescentes, que criou um blog para contar suas aventuras. Esse blog relata as atividades de um grupo terapêutico de jovens, com diferentes necessidades especiais.

O grupo é composto por seis adolescentes de 15 a 21 anos, quatro moças e dois rapazes, como mostra o Quadro 1.

O Participante 1 (P1) é um adolescente de 15 anos, com síndrome de Down, que estuda em uma escola especial, e, apesar de falar, apresenta dificuldade em fazer relatos. O outro rapaz, P2, é o líder do grupo, se expressa muito bem, assume o papel de porta-voz do grupo e está sempre pronto a contribuir. As adolescentes P5 e P6 apresentam bastante autonomia motora e de comunicação, e as moças P3 e P4 são usuárias de cadeira de rodas, apresentam limitaçóes funcionais dos membros superiores, e uma delas fala com dificuldade, enquanto a outra é usuária de comunicação alternativa.

Os aspectos que unem o grupo, e que contribuíram para sua constituição, foram as questôes relacionadas à participação no processo de aprendizagem. As dificuldades no processo de inclusão escolar do sistema de ensino acabaram excluindo dois deles da escola, levou dois dos participantes a precisarem de uma mediadora na sala de aula, uma a necessitar de uma professora particular em casa, e o outro a estudar em uma escola especial.

Associados às dificuldades escolares estão os problemas em fazer amigos, em possuir um grupo para conversar e passear.

Esse grupo, constituído há quase dois anos, já utilizou muitas estratégias para registrar suas atividades. Fizeram um caderno de aventuras, com fotos dos participantes do grupo em suas próprias experiências, e um álbum eletrônico, utilizando o PowerPoint ${ }^{6}$, com fotos das atividades que desenvolveram ao longo de um ano de trabalho, para apresentarem aos pais, na reunião de encerramento do ano de 2010.

Ao descobrirem o blog como ferramenta de registro de suas atividades, começaram a explorá-lo como registro semanal, mas também como um espaço de protesto e solicitaçóes.

Quadro 1. Características do grupo de adolescentes.

\begin{tabular}{|c|c|c|c|c|c|c|}
\hline & $\mathrm{S}$ & Idade & Diagnóstico & Motricidade & Comunicação & Escola \\
\hline P1 & M & 15 anos & $\begin{array}{l}\text { Síndrome de } \\
\text { Down }\end{array}$ & $\begin{array}{l}\text { Sem dificuldade } \\
\text { funcional }\end{array}$ & $\begin{array}{c}\text { Fala, mas } \\
\text { apresenta } \\
\text { dificuldade para } \\
\text { fazer relatos }\end{array}$ & $\begin{array}{l}\text { Está alfabetizado. Estudou até o } \\
5^{\circ} \text { ano em escola regular, como } \\
\text { aluno de inclusão, e, a partir } \\
\text { de } 2011 \text {, está em uma escola } \\
\text { especial, com jovens com } \\
\text { síndrome de Down }\end{array}$ \\
\hline $\mathrm{P} 2$ & M & 14 anos & $\begin{array}{l}\text { Hemiplegia } \\
\text { por sequela de } \\
\text { tumor }\end{array}$ & $\begin{array}{c}\text { Anda com } \\
\text { autonomia, } \\
\text { mas apresenta } \\
\text { dificuldade } \\
\text { para transpor } \\
\text { obstáculos e correr }\end{array}$ & $\begin{array}{l}\text { Fala sem } \\
\text { dificuldade }\end{array}$ & $\begin{array}{c}\text { Está inserido em escola regular, } \\
\text { com uma mediadora }\end{array}$ \\
\hline P3 & $\mathrm{F}$ & 21 anos & Tetraplegia & $\begin{array}{l}\text { Usuária de cadeira } \\
\text { de rodas, pouca } \\
\text { funcionalidade } \\
\text { de membros } \\
\text { superiores }\end{array}$ & \begin{tabular}{|c|} 
Fala com \\
dificuldade \\
articulatória, \\
produzindo uma \\
comunicação \\
pouco funcional \\
\end{tabular} & $\begin{array}{l}\text { Já esteve inserida em escola } \\
\text { regular, mas, atualmente, estuda } \\
\text { em casa, com uma professora } \\
\text { particular }\end{array}$ \\
\hline P4 & $\mathrm{F}$ & 17 anos & Tetraplegia & $\begin{array}{c}\text { Usuária de cadeira } \\
\text { de rodas, sem } \\
\text { funcionalidade } \\
\text { de membros } \\
\text { superiores } \\
\end{array}$ & $\begin{array}{c}\text { Não fala, usuária } \\
\text { de comunicação } \\
\text { alternativa }\end{array}$ & $\begin{array}{c}\text { Já esteve inserida em escola } \\
\text { regular e especial e, atualmente, } \\
\text { estuda em casa, com um } \\
\text { grupo de adolescentes com } \\
\text { dificuldade motora }\end{array}$ \\
\hline P5 & $\mathrm{F}$ & 17 anos & Atáxica & $\begin{array}{l}\text { Anda com } \\
\text { autonomia }\end{array}$ & $\begin{array}{c}\text { Fala com } \\
\text { dificuldade na } \\
\text { entonação }\end{array}$ & $\begin{array}{c}\text { Inserida em escola regular, com } \\
\text { uma mediadora }\end{array}$ \\
\hline P6 & $\mathrm{F}$ & 15 anos & Hemiplegia & $\begin{array}{l}\text { Anda sem } \\
\text { dificuldade }\end{array}$ & \begin{tabular}{|c|} 
Uso pouco \\
funcional do \\
membro superior \\
direito \\
\end{tabular} & $\begin{array}{c}\text { Estuda em escola regular, sem } \\
\text { mediadora, mas precisa de } \\
\text { apoio escolar em casa, com } \\
\text { uma professora particular }\end{array}$ \\
\hline
\end{tabular}


O grupo ficou mais coeso. Eles têm que decidir o que postar, como filmar ou fotografar os temas que querem postar, escolher a cor da fonte, o tamanho da letra, além de se organizar para dividir tarefas no momento da preparação do material e da postagem.

Fazer atividades interessantes, que possam ser relatadas no blog, passou a ser uma preocupaçáo do grupo.

Os participantes divulgam o blog para amigos e familiares, acompanham e respondem os comentários que recebem, e consultam as informaçóes do blog quando náo podem estar presentes aos encontros semanais do grupo. Um dos componentes do grupo, que terminou o ensino fundamental, iniciou um novo blog para escrever sobre o turismo no Rio de Janeiro, discutindo questóes como acessibilidade para pessoas com deficiência.

Finalmente, o terceiro caso é de uma moça com quadro de paralisia cerebral atetoide, de 17 anos, que escreveu e publicou um livro, com o auxílio das estratégias de comunicação alternativa, e posteriormente construiu um blog para contar como conseguiu escrever, e que tipo de recursos utilizou.

Mariana possui quadro de paralisia cerebral do tipo atetose, e apresenta-se com controle regular de cabeça, impossibilidade de se manter sentada sem suporte, ficar de pé ou andar, dificuldades para utilizar as mãos funcionalmente, e ausência de comunicação oral. Seu tônus muscular flutua entre a hipotonia e a hipertonia, com acentuada movimentação involuntária, principalmente de membros superiores.

Para possibilitar ou ampliar a participação de pessoas com dificuldades motoras nas atividades diárias, a tecnologia assistiva se mostra essencial. A tecnologia assistiva envolve áreas como: comunicação alternativa e ampliada; mobilidade alternativa; posicionamento adequado; acesso ao computador; adaptaçôes às atividades de vida diária; aos ambientes; aos transportes; e aos equipamentos de lazer e recreação (BARNES; TURNER, 2001).

Para se comunicar, faz uso de uma comunicação alternativa com símbolos, recursos, estratégias e técnicas apropriadas às suas necessidades.

Um dos recursos de comunicação que utiliza é uma prancha com símbolos pictográficos, em forma de caderno, com 12 a 24 símbolos por página, que estâo organizados por assuntos como: "sobre mim", "tópicos de conversa", "fazer perguntas", "açôes", "sentimentos", "lugares", "objetos", "atividades preferidas", entre mais de 80 páginas. As folhas possuem uma aba, com o número da página e o assunto, e o parceiro de comunicação é conduzido às outras páginas da prancha, pela indicação dos números que estâo inseridos acima dos símbolos. Por exemplo: quando diz que quer "contar alguma coisa", há um número sobre o símbolo de "contar alguma coisa” que indica, ao parceiro de comunicação, que ele deve virar a página para o índice, onde estão listados os assuntos de sua prancha, para que ela possa escolher sobre o que quer falar.

Além da prancha de comunicação, utiliza um programa de computador, o Speaking Dynamically ${ }^{7}$, que funciona por sistema de varredura. Por meio desse programa, Mariana consegue se comunicar, utilizando um acionador externo, fixado no seu apoio de cabeça.

Contudo, a estratégia mais rápida é a de perguntas do tipo "Sim" e "Não", que ela responde com o olhar, movimentos de cabeça ou produção de sons, que entáo passa a ser a estratégia mais utilizada para a solução de problemas rotineiros.

Recentemente, essa moça escreveu um livro sobre um rei e uma rainha, utilizando uma prancha de alfabeto, que era apontada por sua mediadora. A mediadora indicava as linhas, e quando chegava à linha da letra que Mariana queria, ela balançava a cabeça, fazia algum som ou olhava para a mediadora.

Foram escritas 29 folhas em tamanho A3, com uma ou duas frases em cada uma. Essa etapa teve a duração de 16 encontros de três horas cada, distribuídos em 26 dias - período em que ficou sem aula, por falta de professora.

Após o término da história, a mediadora fez a revisão do texto com ela, corrigindo a ortografia das palavras. A partir dessa etapa, o material passou a ser trabalhado nas sessóes de Terapia Ocupacional. O texto foi reescrito no computador e revisto, frase por frase, por ela. As principais modificaçóes nessa fase envolveram a adequação de adjetivos, substituição de palavras repetidas e alteraçóes quanto à pontuação. Os adjetivos foram apresentados alguns mais pertinentes e seus sentidos discutidos. Só foram modificados os termos que tiveram a sua concordância, em um trabalho com duração de seis semanas, com um encontro por semana.

Com a finalização do texto, foi discutido o formato do livro. Foram apresentadas algumas opções e analisadas as características de cada uma, até a escolha final.

O livro foi ilustrado com pinturas da própria Mariana, a partir do uso de um apontador de cabeça, da mão e de um pincel adaptado a sua mão. Foram criadas ilustraçôes para cada uma das páginas. Sua máe lia a página do livro que precisava ser ilustrada, e a partir dessa informação eram escolhidas as cores 
da tinta e o instrumento que seria utilizado. Essas ilustraçóes foram fotografadas e incluídas na versão digitalizada.

Depois de escolhida a editora, as próximas etapas foram a redação dos agradecimentos e a escolha da forma e do conteúdo da apresentaçáo da autora e de sua foto.

Para divulgar o trabalho, e contar a história de como o livro foi elaborado, Mariana e sua terapeuta ocupacional construíram um blog.

Cada uma das etapas foi filmada e postada no blog, com as explicações necessárias. Para a criação do blog foram utilizados os recursos de comunicaçáo alternativa que Mariana dominava, e ela, apesar da limitação motora e comunicativa, foi a autora do processo, tomando as decisões e comandando as diferentes fases.

As estratégias utilizadas possibilitaram a Mariana o alcance da competência e da satisfação no seu papel como escritora, em consonância ao objetivo do trabalho da Terapia Ocupacional (LAW, 2005).

O uso da tecnologia assistiva, com recursos adaptados para a escrita e comunicação, e a utilização do blog como uma estratégia de divulgaçáo do seu trabalho foram fundamentais nesse processo.

Para finalizar essa apresentaçáo podemos dizer que pessoas com histórias de vida singulares, com habilidades, limitaçôes e desejos diversos, utilizaram o blog como atividade terapêutica.

Para cada cliente, pessoa ou grupo, a atividade foi conduzida de maneira diferente. Para João foi fácil compreender os mecanismos de salvar e utilizar as imagens da internet no seu blog, para alguns dos participantes do grupo de adolescentes foi necessário salvar previamente as imagens no Picasa, aplicativo de compartilhamento de imagens do Google, para que elas só precisassem ser escolhidas. Para Mariana, essa mesma estratégia foi utilizada, mas teve que ser acrescida da varredura manual, sobre cada uma das fotos, até que ela sinalizasse a foto desejada.

A escrita dos textos também foi conduzida de maneira distinta. Para João, o que deveria ser escrito estava na sua cabeça, mas a forma da escrita precisava de ajustes. Muitas vezes, os textos foram relidos e foram necessários ajustes; para os adolescentes, um pequeno texto podia demorar uma hora para ser escrito. Tudo precisava ser discutido: a cor da fonte, o tamanho da letra, o que seria escrito, por quem seria escrito e sobre qual perspectiva, se dramática, engraçada ou questionadora. Mariana escrevia seus textos com o auxílio de seu programa de comunicação alternativa no computador ou a partir da escolha dos temas na prancha de comunicação, e de alternativas de frases que eram oferecidas pela terapeuta e por sua mãe.

O post pode ser escrito em uma única sessão, ou em várias, porque é possível salvar um rascunho, sem publicar, e continuar depois a escrever. Ele também permite correção, pois a qualquer momento é possível rever um post e acrescentar fotos, filmes ou mais informaçōes.

O blog não exige uma frequência de postagem, podendo ser uma das atividades realizadas na terapia ao longo do mês, ou não. $\mathrm{O}$ cliente pode se identificar com fotos e relatos pessoais ou do seu grupo, ou pode fazer um blog sem nenhuma identificação, e essa última escolha deve ser partilhada com as famílias dos clientes, para que o terapeuta tenha autorização dos pais para a exposição de fotos ou dados pessoais na internet.

São tantas as possibilidades que hoje o blog vem sendo usado com os propósitos mais diversos: como jornal, que permite a opinião do autor, sem a preocupação da censura do editor, sobre assuntos variados; para partilhar fotos ou notícias de viagens ou eventos; como recurso instrucional para diferentes categorias profissionais; como forma de avaliação de universitários em inúmeras disciplinas; como recurso de divulgaçáo profissional; ou como um diário pessoal, que favorece a interação com pares na rede virtual.

E por que não como recurso terapêutico ocupacional? Por ter um uso táo diversificado e possibilitar diferentes estratégias, pode ser mais explorado pelo terapeuta ocupacional desse novo século.

\section{Referências}

AMERICAN OCCUPATIONAL THERAPY ASSOCIATION - AOTA. Broadening the Construct of Independence. American Journal of Occupational Therapy, New York, v. 56, p. 660, 2002. Position Paper. http://dx.doi.org/10.5014/ajot.56.6.660

BARNES, K. J.; TURNER, K. D. Team Collaborative Practices Between Teachers and Occupational Therapist. The American Journal of Occupational Therapy, New York, v. 55, n. 1, p. 83-9, Jan./Feb. 2001. http://dx.doi. org/10.5014/ajot.55.1.83

CANADIAN ASSOCIATION OF OCCUPATIONAL THERAPISTS - CAOT. Position Statement: Assistive Technology and Occupational Therapy. Canadian Journal of Occupational Therapy, Ottawa, v. 70, n. 2, p. 113-8, Apr. 2003.

GOLDMAN, R. H.; COHEN, A. P.; SHEAHAN, F. Using Seminar Blogs to Enhance Student Participation and Learning in Public Health School Classes. American Journal of Public Health, Birmingham, v. 98, n. 9, p. 1658-1663, 
Sept. 2008. PMid:18633075 PMCid:2509603. http:// dx.doi.org/10.2105/AJPH.2008.133694

GWOZDEK, A. E.; KLAUSNER, C. P.; KERSCHBAUM, W. E. The utilization of Computer Mediated Communication for case study collaboration. Journal of Dental Hygiene, Chicago, v. 82, n. 1, p. 8-18, 2008.

LAW, M. Avaliando papéis e competência. In: TROMBLY, C. A.; RADOMSKI, M. V. (Orgs.). Terapia ocupacional para disfunções físicas. Tradução de Beatriz Bitterncourt Granjo Schlecht Denes. São Paulo: Livraria Santos Editora Ltda, 2005. p. 31-46.

LiMA, N. L.; SANTIAGO, A. L. B. Por que os adolescentes escrevem diários na rede? Pesquisas e Práticas Psicossociais, São João del Rei, v. 5, n. 1, p. 53-64, jan./ jul. 2010.

LUCCIO, F.; NICOLACIDA-COSTA, A. M. Blogs: De diários pessoais a comunidades virtuais de escritores/ leitores. Psicologia, Ciência e Profissão, Brasília, v. 30, n. 1, p. 132-145, 2010. http://dx.doi.org/10.1590/ S1414-98932010000100010

OMURTAG, K. et al. The ART of Social Networking: how SART member clinics are connecting with patients online. Fertility and Sterility / American Society for the Study of Sterility, Philadelphia, v. 97, n. 1, p. 88-94, Jan. 2012. PELOSI, M. B. Comunicação Alternativa e Suplementar. In: CAVALCANTI, A.; GALVÃO, C. (Orgs.). Terapia Ocupacional: Fundamentação \& Prática. Rio de Janeiro: Guanabara Koogan, 2007. p. 462-468.

SHUSTER, N. E. Addressing Assistive Technology Needs in Special Education. The American Journal of Occupational Therapy, New York, v. 47, n. 11, p. 993-7, Nov. 1993. http://dx.doi.org/10.5014/ajot.47.11.993

SUBRAHMANYAM, K. et al. In their Words: connecting on-line weblogs to developmental processes. British Journal of Developmental Psychology, Leicester, v. 27; Part 1, p. 219-45, Mar. 2009. http://dx.doi. org/10.1348/026151008X345979

\section{Notas}

${ }^{1}$ Parte das reflexôes aqui mostradas foi apresentada no XII Congresso Brasileiro de Terapia Ocupacional e IX Congresso Latino-Americano de Terapia Ocupacional, 2011, São Paulo, Brasil.

${ }^{2}$ HTML - Hyper Text Markup Language, que significa Linguagem de Marcação de Hipertexto, e é uma linguagem de marcaçáo utilizada para produzir páginas na web. Todo documento HTML apresenta etiquetas, elementos entre parênteses angulares < e >; esses elementos são os comandos de formatação da linguagem. Uma etiqueta é formada por comandos, atributos e valores. Os atributos modificam os resultados-padráo dos comandos, e os valores caracterizam essa mudança. Por exemplo: $<$ HR color="red"/ $>$. No qual: $\mathrm{HR}=$ comando que insere uma linha horizontal; color = atributo que especifica a cor da linha; red = valor do atributo "color", que irá alterar a cor da linha.

${ }^{3}$ YouTube é um site que permite que os usuários carreguem e compartilhem vídeos em formato digital. Foi fundado em fevereiro de 2005, e o material encontrado nele pode ser disponibilizado em blogs e sites pessoais, por meio de mecanismos desenvolvidos pelo site.

${ }^{4} \mathrm{~A}$ Google é uma empresa multinacional de serviços on-line e software, dos Estados Unidos. Foi fundada como uma empresa privada, em 1998, por Larry Page e Sergey Brin, e sua oferta pública inicial foi realizada em 19 de agosto de 2004. A missáo declarada da empresa, desde o início, foi a de organizar a informação mundial e torná-la universalmente acessível e útil.

${ }^{5} \mathrm{O}$ Google Imagens é um serviço de busca prestado pela empresa Google, que consiste em procurar imagens dos mais diversos tipos na internet.

${ }^{6} \mathrm{O}$ software PowerPoint compóe o conjunto de aplicativos do pacote Microsoft Office, e é comumente utilizado como recurso para apresentação de ideias em situaçôes de trabalho e estudo. Ele é um programa facilmente customizado e foi uma excelente ferramenta para a construção do álbum eletrônico do grupo.

7 O software Speaking Dynamically Pro - SDP transforma o computador em um eficaz recurso de educação e de comunicação alternativa. É um programa fácil de usar e que trabalha integrado ao Boardmaker, permitindo criar inúmeras atividades interativas educacionais e de comunicaçáo com acessibilidade total. $\mathrm{O}$ acesso ao programa pode ser feito com o auxílio do mouse, teclado ou através de acionadores externos através dos sistemas de varredura. 
